\title{
Novel Knitting Model Based on Automation and Industry 4.0
}

\author{
Gabriela Maestri, Fernando Ribeiro Oliveira, Eduardo Werner Benvenuti and Fernanda Steffens* \\ Federal University of Santa Catarina Blumenau, Brazil
}

*Corresponding author: Fernanda Steffens, Textile Engineering Post Graduate Program (PGETEX), Federal University of Santa Catarina Blumenau, SC, Brazil.

Received Date: October 09, 2020

Published Date: November 04, 2020

\begin{abstract}
The textile industry is composed by a complex chain, which comprises several sectors. Each area presents its particularities during product development. Among the sectors, one that stands out is the knitting, as it presents some advantages in relation to the others, such as low financial investment employed, in addition to being very versatile. However, this sector still has many activities carried out manually. Nowadays, technological innovations have opened the way for realizing the smart factory vision with the fourth industrial revolution, which has significant potential to change the whole manufacturing processes and business models. Thus, the objective of this study is to present a new configuration for the knitwear segment, which includes concepts related to industry 4.0 integrated with the processes of the textile sector. For that, a knitting industrial layout plan was developed using the Factory $I O \AA$ software, in order to operate with autonomy and connectivity through the use of emerging technologies. Based on this, compared to the empirical data of a conventional knitting industry, an increase in the control of the processes in real time of the product quality and operator ergonomics are expected, estimating a gain in time of approximately $27 \%$, in addition to data storage.
\end{abstract}

Keywords: Industry 4.0; Textile; Weft knitted; Enabling technologies; Process automation; Smart factory

\section{Introduction}

The textile industry is considered by being a complex chain, comprising several sectors, from the production of fibers to the development of the final product [1-2]. In this chain, the most wellknown processes are spinning, weaving, knitting, dyeing, finishing, printing, nonwovens, apparel and treatment of water and effluents $[1,3]$. A brief overview of the complexity of the textile industry can be seen in Table 1.

According to Table 1 it is possible to observe the high number of sectors and branches involved in the textile universe, presenting great potential for the development of new products [4]. This complexity makes it possible to include technologies both in its development and manufacturing process as well as automation, interoperability and connectivity, which are the result of concepts related to industry 4.0; or in the final product, through for example, intelligent and functional agents $[5,6]$.
In order to guarantee control of the production process, some textile industries are vertical, that is, they have machinery that comprises the processes from spinning to apparel the final product. Other companies, however, present themselves as suppliers of products for the subsequent steps. An example is the knitting industry, which provides the knitted fabric for the clothing industry [7].

It also highlights the importance of the Brazilian textile industry, which stands out for being the largest complete textile chain in the West, producing from fibers to the final product manufactured, operating in Brazilian territory for almost 200 years [8].

Economically, the Brazilian textile sector has always been extremely important [9], and, currently, it has billing of textiles and clothing products of approximately US\$ 50 billion. Brazil is also the world's fourth largest producer and consumer of denim and the fourth largest producer of knitted fabric in the world. Currently, the 
textile sector has 1.5 million direct employees and 8 million indirect employees, of which $75 \%$ are made up of female labor, representing around $17 \%$ of jobs in the entire manufacturing industry, inserted in 27,500 companies across the country [8].

The knitting industry has interesting characteristics when compared to other sectors of the textile segment. It can be said that the sector does not demand a high financial investment, in addition to not needing a preparation sector (sizing), as is the case with weaving. Depending on the raw material and structure used to produce, manufacturing costs are low. In addition, the knitting sector allows the introduction of new technologies adapted to its production cycle. Further to conventional products related to clothing, the increasing popularity of knitted fabrics allowed its insertion in the fashion market, and compared to other industries in the textile segment, knitting is the sector that provides greater development of new products [1]. Some examples are vascular protheses [10]; high-performance sporting products, such as threedimensional knitted structures to provide impact absorption, thermal comfort, and flexibility [11-14]; insertion of electronics in knitted structures, so that the resulting products monitor the user, such as the quality of his breathing, step count, heartbeat $[15,16]$; insertion of electronics in products aimed at the biomedical area, where socks monitor body functions and vibrate to assist blood circulation in diabetic patients [17], among others.

Even considering all the advantages mentioned in relation to the knitting sector, many of the activities involved in this industry are still carried out manually, such as: the equipment setup, that is, the complete alteration of all elements for the development of a new knitted fabric pattern; transport of produced knitted rolls; splice the yarns; placing yarn packages to feed the knitting machine. The activities currently performed manually during setup on a weft circular knitting machine can be seen in Table 2 .

Table 1: Areas of textile industry.

\begin{tabular}{|c|c|c|c|}
\hline \multicolumn{2}{|r|}{ Area } & Description & Products obtained \\
\hline \multirow[t]{3}{*}{ Spinning } & From natural fibers & $\begin{array}{l}\text { Processes that transform natural substrates into yarns, classified } \\
\text { according to their origin }\end{array}$ & $\begin{array}{l}\text { The most common natural yarn is cotton. } \\
\text { Linen, wool and silk also stand out }\end{array}$ \\
\hline & $\begin{array}{l}\text { From regenerated } \\
\text { fibers }\end{array}$ & $\begin{array}{l}\text { Cellulosic material is transformed into cut filaments/fibers, clas- } \\
\text { sified according to the type of process used and solvent used }\end{array}$ & Viscose and acetate yarns stand out \\
\hline & From synthetic fibers & $\begin{array}{l}\text { Process from the polymerization of monomers, resulting in a } \\
\text { viscous mass that passes through spinneret }\end{array}$ & $\begin{array}{l}\text { They can be filaments or staple fibers. The } \\
\text { polyester, polyamide, elastane yarns stand out }\end{array}$ \\
\hline \multicolumn{2}{|r|}{ Weaving } & $\begin{array}{l}\text { First, the yarns are sized, due to the high tensions that will be } \\
\text { subjected. Through the crossing of the weft and warp yarns, } \\
\text { woven fabrics are formed }\end{array}$ & $\begin{array}{l}\text { Woven fabric in different patterns such as } \\
\text { taffeta, satin twill and their derivatives }\end{array}$ \\
\hline \multirow[t]{2}{*}{ Knitting } & By weft & $\begin{array}{l}\text { Knitting process where loops are formed in the horizontal } \\
\text { direction. Circular (single-cylinder and cylinder and dial) and flat } \\
\text { knitting machine (mono and double front) }\end{array}$ & $\begin{array}{l}\text { Knitted fabrics in different rapports like jersey, } \\
\text { rib, interlock, purl and their derivatives }\end{array}$ \\
\hline & By warp & $\begin{array}{l}\text { Knitting process where loops are formed in the vertical direction. } \\
\text { Raschel and Ketten machine }\end{array}$ & $\begin{array}{l}\text { Knitted fabrics in different rapports such as } \\
\text { knitting, locknit, lace, spacer, among others }\end{array}$ \\
\hline \multicolumn{2}{|r|}{ Nonwoven } & $\begin{array}{l}\text { Processes where webs of fiber or filaments can be formed using } \\
\text { air-laid, wet-laid and spun melt. Sheet or web structures are } \\
\text { bonded by mechanical entanglement, chemical or thermally }\end{array}$ & $\begin{array}{l}\text { Thermal and acoustic insulation webs, dispos- } \\
\text { able diapers, baby wipes, face masks, filters }\end{array}$ \\
\hline \multicolumn{2}{|r|}{ Dyeing } & $\begin{array}{l}\text { It is possible to dye fibers, yarns, fabrics or even finished prod- } \\
\text { ucts. It requires the preparation of the substrate and water is } \\
\text { normally used as a solvent. Each type of fiber requires a specific } \\
\text { class of dyes and chemicals auxiliaries }\end{array}$ & Color uniformity on the textile substrate \\
\hline \multirow[t]{2}{*}{ Finishing } & Physical & $\begin{array}{c}\text { They provide modifications to the materials through physical } \\
\text { processes, such as brushing, napping, shearing or singeing, } \\
\text { among others, or even more sophisticated through plasma } \\
\text { discharge }\end{array}$ & $\begin{array}{l}\text { Surface modification of the substrate, such as } \\
\text { plush }\end{array}$ \\
\hline & Chemicals & $\begin{array}{l}\text { The substrate is modified with the use of chemical agents/pro- } \\
\text { cesses, }\end{array}$ & $\begin{array}{l}\text { Anti-UV, bactericidal, flameproof, chromic fin- } \\
\text { ishes, shape memory, phase change materials, } \\
\text { hydrophilic and hydrophobic surface modifica- } \\
\text { tions, among others }\end{array}$ \\
\hline \multicolumn{2}{|r|}{ Apparel } & $\begin{array}{c}\text { It encompasses the spreading processes (which will organize the } \\
\text { substrate into layers, according to the quantity to be produced); } \\
\text { cutting and sewing. The most common machines are single } \\
\text { needle lockstitch and overlock }\end{array}$ & $\begin{array}{l}\text { Various products can be manufactured, from } \\
\text { conventional clothing (dresses, pants, T-shirts), } \\
\text { to technical products made of high-perfor- } \\
\text { mance yarns, such as parachutes, airbags, } \\
\text { ballistic vest, among others }\end{array}$ \\
\hline \multicolumn{2}{|c|}{ Textile Printing } & $\begin{array}{l}\text { Process by which color is applied to a textile surface from a spe- } \\
\text { cific design and method. Examples of printing processes: digital, } \\
\text { flat bed and rotary screen printing, transfer and sublimation }\end{array}$ & Obtaining a design/effect on the substrate \\
\hline \multicolumn{2}{|c|}{ Water and effluent treatment } & $\begin{array}{l}\text { Process responsible for treating the water to be used in the } \\
\text { textile processes and the effluents generated, removing color, } \\
\text { smell, toxic substances and other unwanted aspects. Among the } \\
\text { applied techniques are activated sludge, membrane filtration and } \\
\text { chemical oxidation }\end{array}$ & Clean and treated water \\
\hline
\end{tabular}


Table 2: Activities perform during setup.

\begin{tabular}{|c|c|}
\hline Step & Description \\
\hline 1 & Positioning of the cams according to the knitted structure that will be produced \\
\hline 2 & Placing yarn packages in knitting machine creel \\
\hline 3 & Yarn passing through all knitting elements, such as feeders and needles \\
\hline 4 & Initial tests and knitted fabric production \\
\hline 5 & Knitted fabric cutting (after finished) \\
\hline 6 & Positioning of the knitted roll produced in fabric inspection machine \\
\hline 7 & Review and winding the knitted fabric \\
\hline 8 & Delivery of the finished knitted roll to the pallet \\
\hline
\end{tabular}

As noted in Table 2, the activities that comprise the knitting sector setup are carried out manually. During the production process, the operator is involved with other knitting machines in the same sector, working on the splicing of yarns, loading of knitted fabrics that are being finalized, preparation of new setups, observation of defects, among others. That is, the operator is working in manual activities and many of them are repetitive and may even involve high physical effort.

\section{Ergonomic factors inserted in the knitting industry}

As shown in Table 1, the textile sector has different subdivisions, which allows for improvements in its processes [18]. Among them, it can mention the issue of ergonomics, which must be considered in any industrial process [19]. Activities carried out under inadequate conditions can seriously harm human health, leading to minor injuries, inactivity, and, in extreme cases, can lead to death $[20,21]$.

In the textile industry, there are several reports that show dissatisfaction related to activities in which ergonomics is neglected.
Examples are the high level of noise and/or vibrations, excessively high temperatures, repetitive movements and poor posture during operations $[22,23]$.

Given this, one of the current problems that the Brazilian scenario of the knitting industry faces is associated to risks related to ergonomic issues, and among them, the high weight of the knitted fabric rolls (15 to $25 \mathrm{~kg}$ ) stands out, which when finished, are removed from the knitting machine and often transported without suitable equipment by the operator. Another problem is the evaluation of the quality of the knitted fabric produced by the visual method, which after a few hours implies fatigue and irritation to the eyes, as it is a repetitive activity [24]. Figure 1 illustrates an example of a situation in which the operator stands in front of the equipment, analyzing the knitted fabric that passes continuously for a long period. In addition, it is estimated that the accuracy of this activity, when performed manually, is approximately $70 \%$, as it is influenced by operator fatigue [25].

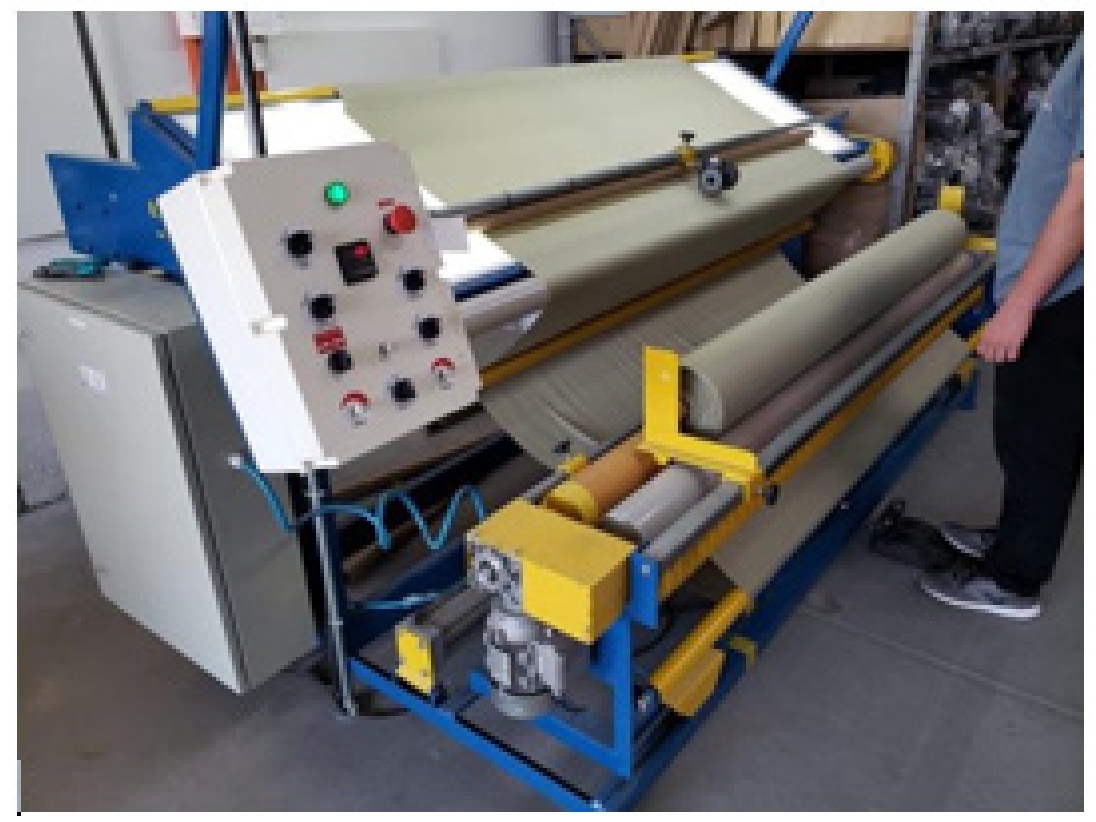

Figure 1: Current knitted fabric inspection process. 
Technological advancement starting with the automation of processes and the aid of specifics software, depending on the area, a new configuration for the job is verified. Activities that were performed manually are transformed into new occupations, with less physical effort and high productivity for the sector [26].

For this reason, the emerging technologies that make up Industry 4.0 are efficient when related to the transformation of jobs to offer superior quality and productivity, both for industries and for employees, since they are interconnected all the time. The tools that together support Industry 4.0 are: robotics; internet of things; simulation; additive manufacturing; augmented reality; data processing and analysis; cloud computing and cyber-physical systems [27-30].

It is also possible to state that Industry 4.0 operates in virtualization, interoperability, real-time capacity and service orientation. The combination of all these technologies becomes the corporation an Industry 4.0 [31].

Thus, the aim of this study is to develop an innovative circular weft knitting industrial plan, defined as "Knitting 4.0". From the introduction of enabling technologies, it is intended to obtain satisfactory results related to the control and quality of the process and, consequently, of the product, as well as the activities of the employee, avoiding manual work that may put their health and well-being at risk. The main contribution is that the knitting industry continues being a competitive textile sector in the global market, having seen the implementation of futuristic industrial technologies. In addition, the intention is to empirically compare the productivity of this "new" knitting layout plan to a conventional one that operates with current market resources.

\section{Methodology}

The production and machine setup time in knitting are directly influenced by the type and quality of raw material (yarn), type of knitting machine, degree of operators' instruction and complexity of the rapport of the knitted fabric. Even the layout of the company's production and of the operator's tools interferes with the adjustment times of the machine. Therefore, due to all these factors that involve the production of knitted fabrics, it is difficult to determine average of times for each activity performed during the setup, which would be valid for any type of fiber, yarn, rapport and machinery. In this way, a specific model of machine configuration was determined, as a way of obtaining more reliable time parameters, which could be used to verify the effectiveness of any improvement performed in the setup process in a hypothetical Knitting 4.0.

To determine the model mentioned, some of the main Brazilian suppliers of circular knitting machine and their accessories were checked. The consultations sought to determine technical specifications of the circular weft knitting machine offered on the market; the main types of circular weft knitting machine sold in 2019; the possible ways of arranging the yarn spools for feeding in the circular weft knitting machine. Posteriorly, as a manner of empirically verifying the information collected, as well as estimating production time for the chosen rapport, a knitting industry that could assist in the research was requested to participate, presenting its layout, machinery and production process. The knitting industry chosen for the research is located in the Itajaí Valley, a region of the State of Santa Catarina in Southern Brazil, known for being a textile cluster [32].

In order to estimate the production and setup time observed in the knitting company, a specific knitted fabric was selected, manufactured on a circular weft knitting machine that meets the requirements of this investigation. Additionally, the mechanics of the company were consulted to validate the production time obtained. The rapport of weft knitted fabric chosen to produce was single jersey, with a composition of $88 \%$ textured polyester and $12 \%$ elastane.

Based on the aforementioned characteristics, related to the main activities of operators in the knitting sector, and considering the emerging technologies of Industry 4.0, with the support of the industrial automation software Factory $I O \AA$, an innovative "Knitting 4.0" plan was developed, which will be presented in different perspectives.

In this sense, the industrial plan has, in addition to circular weft knitting machine, the introduction of sensors, automatic mats, camera and automatic scale at the end of the process. It is important to mention the connectivity between each step, so that the information is recorded, ensuring total control of the knitting sector.

\section{Results and Discussion}

According to the market research carried out, it was found that single knitting machine would be an adequate option for the objectives of the work, as they are widely disseminated and commonly found in knitting industries. In addition, knitting machine manufacturers point out that they work at higher rotation speeds than double knitting machine, resulting in superior productivity for certain types of products.

Regarding the manners in which yarn packages are placed for feeding the knitting machine, the manufacturers emphasize that depends on the knitted fabric patterns manufactured and the available space of the companies. For the manufacture of synthetic fiber products, for example, the bilateral arrangement of supports is used, reducing the abrasion of the yarn.

Table 3: Machine specification.

\begin{tabular}{|c|c|}
\hline Type of knitting machine & Circular \\
\hline Type of knitting & Weft knitting \\
\hline Make & Pilotelli JC 3.0 \\
\hline
\end{tabular}




\begin{tabular}{|c|c|}
\hline Frame: & Single knitting machine \\
\hline Cylinder diameter & $32^{\prime \prime}$ \\
\hline Gauge & $28^{\prime \prime}$ \\
\hline No. of needles & 2760 \\
\hline No. of feeders: & 96 \\
\hline No. of cam tracks & 1 \\
\hline
\end{tabular}

Based on the type of weft knitted fabric produced and the variety of knitting machine at the company studied, it was found that the most used circular weft knitting machine is exactly the single one with two creels. Machine specification is presented in Table 3.
The next step was to survey the production times. After consulting the company's technicians and mechanics, as well as factory managers, it was noted that there are well-defined times for each manufacturing step of the aforementioned product, robust enough to be used even as a basis for product pricing (Figure 2).

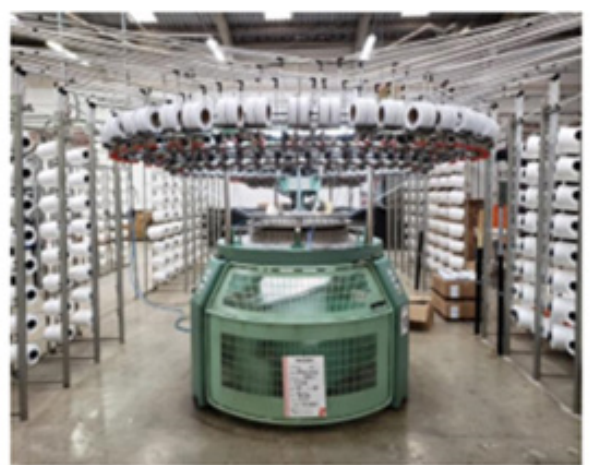

a

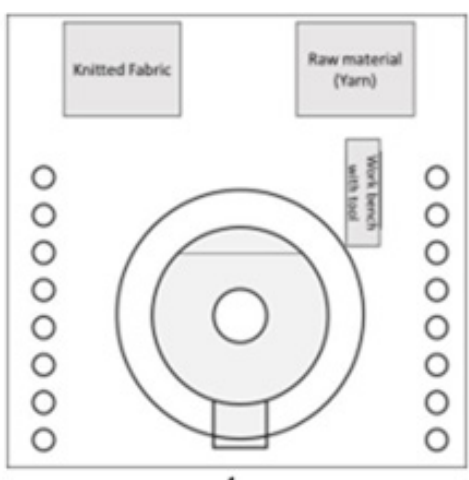

b

Figure 2: Presentation (a) and layout of materials arranged on the knitting machine (b).

It is also worth mentioning that the production time cited in Table 4, in the "complete setup", are for situations in which the circular knitting machine is without configured cams, as well as the yarns have not yet been inserted in the creel, therefore, the knitting machine was not in production previously. For situations where Table 4: Duration of production steps of the knitted fabric studied.

\begin{tabular}{|c|c|c|c|c|c|}
\hline \multirow[t]{2}{*}{ Step } & \multirow[t]{2}{*}{ Description } & \multicolumn{2}{|r|}{ Completed setup } & \multicolumn{2}{|r|}{ Reduced setup } \\
\hline & & Time [min] & Comments & Time [min] & Comments \\
\hline 1 & $\begin{array}{l}\text { Positioning of cams according to the } \\
\text { knitted fabric pattern that will be } \\
\text { produced }\end{array}$ & 120 & & - & Cams are already positioned \\
\hline 2 & Placing yarn packages in the creel & 45 & & 15 & Yarns replacement \\
\hline 3 & $\begin{array}{l}\text { Yarn passing through all knitting } \\
\text { elements (feeders and needles) }\end{array}$ & 30 & & - & Yarns are already inserted \\
\hline 4 & $\begin{array}{l}\text { Initial tests and knitted fabric pro- } \\
\text { duction }\end{array}$ & 20 & & 2 & $\begin{array}{l}\text { Checking for possible defects and } \\
\text { adjustments }\end{array}$ \\
\hline 5 & Production of the first roll & 35 & $\begin{array}{l}\text { To produce 16kg according to } \\
\text { the technical datasheet ( } 80 \% \\
\text { efficiency) }\end{array}$ & 35 & $\begin{array}{l}\text { To produce } 16 \mathrm{~kg} \text { according to the } \\
\text { technical datasheet, (80\% efficien- } \\
\text { cy) }\end{array}$ \\
\hline 6 & Cutting knitted fabric (after finished) & 1 & & 1 & \\
\hline 7 & $\begin{array}{l}\text { Positioning of the newly produced } \\
\text { knitted roll in the revisor }\end{array}$ & 2 & $\begin{array}{l}\text { Only the first roll of each produc- } \\
\text { tion batch is reviewed }\end{array}$ & 2 & $\begin{array}{l}\text { Only the first roll of each production } \\
\text { batch is reviewed }\end{array}$ \\
\hline 8 & Review and winding of the fabric & 8 & & 8 & \\
\hline 9 & $\begin{array}{l}\text { Delivery of the finished knitted roll to } \\
\text { the pallet }\end{array}$ & 1 & & 1 & \\
\hline
\end{tabular}

the knitting machine is already producing the desired product, it is stated that it is a "reduced setup". Production time, both for the complete and for the reduced setup, with the respective comments, is presented in Table 4. It is important to note that one operator was considered for the execution of each step. 


\begin{tabular}{|c|c|c|c|c|c|}
\hline 10 & $\begin{array}{c}\text { Production of the subsequent knitted } \\
\text { roll }\end{array}$ & 35 & $\begin{array}{c}\text { To produce 16kg according to } \\
\text { the technical datasheet (80\% } \\
\text { efficiency) }\end{array}$ & 35 & $\begin{array}{c}\text { To produce } 16 \mathrm{~kg} \text { according to the } \\
\text { technical datasheet (80\% efficiency) }\end{array}$ \\
\hline 11 & Cutting fabric (after finished) & 1 & & 1 & 1 \\
\hline 12 & $\begin{array}{c}\text { Delivery of the finished knitted roll to } \\
\text { the pallet }\end{array}$ & 1 & & & 1 \\
\hline
\end{tabular}

In order to determine the production time for step 5 and 10, the company considers all the parameters of the product technical datasheet, but also takes into account possible knitting machine failures and yarn breakage, factors that decrease the efficiency of the production process.

Due to the slowness involved in the revision process, the company completely revises only the first roll of each production batch. However, all the others are visually monitored by the operator during their production on the knitting machine. To determine the time of step 8, it is considered that the reviewer equipment works with a fixed speed of operation, even if this parameter can be adjusted according to the knitted pattern, yarn, among other variables.

For a complete analysis, the total production time must be determined according to the size of the production batch to be Table 5: Production time by batch size and setup configuration.

\begin{tabular}{|c|c|c|c|}
\hline \multirow{2}{*}{ Setup } & Batch size [rolls] & Total time [min] & Time/Roll [min] \\
\hline \multirow{2}{*}{ Complete } & 07 & 484 & 69,1 \\
\cline { 2 - 4 } & 20 & 965 & 48,3 \\
\hline \multirow{2}{*}{ Reduced } & 07 & 286 & 40,9 \\
\cline { 2 - 4 } & 20 & 767 & 38,4 \\
\hline
\end{tabular}

From the mentioned concepts related to the automation of the knitting sector to increase productivity and control, and also, taking

into account ergonomic aspects, the industrial plan in different perspectives is presented in Figures 3-7. manufactured. Analyzing the fabrication of a roll in isolation makes the production time of it extremely long, since the setup time is diluted in just one roll. Therefore, according to the batch formation restrictions for the subsequent dyeing processes, the company forms batches of 7 or 20 rolls, the equivalent of $112 \mathrm{~kg}$ or $320 \mathrm{~kg}$, respectively. It is important to note that for the product studied (single jersey knitted fabric), it is manufactured and folded (not in rolls). Nevertheless, times do not change. Table 5 shows the production time to manufacture batches of 7 or 20 rolls, for situations of complete and reduced setup.

From the analysis of Table 5 and in view of the restriction formation of well-defined batch sizes, it is possible to describe the potential improvements resulting from the automation of the knitting manufactory, due to the technologies that involve the industry 4.0 .

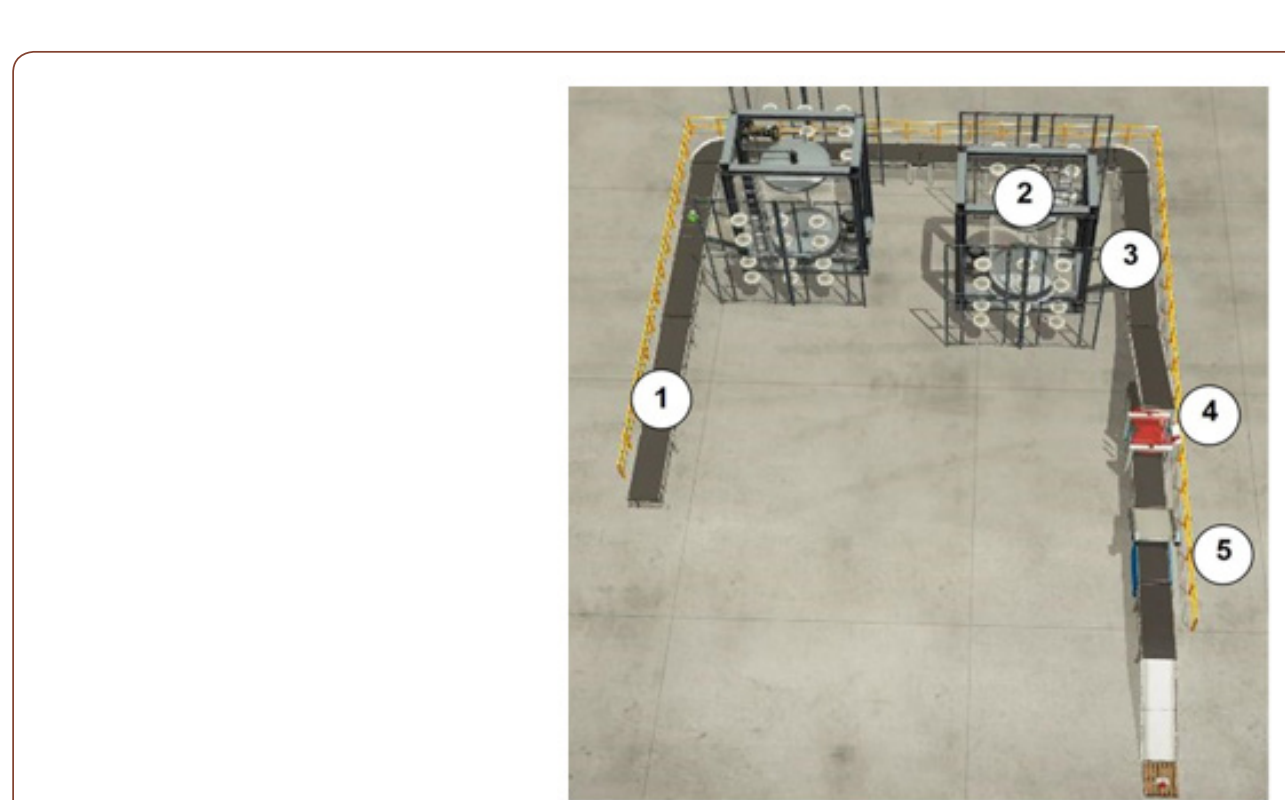

Figure 3: Top view of the Knitting 4.0 plan. 


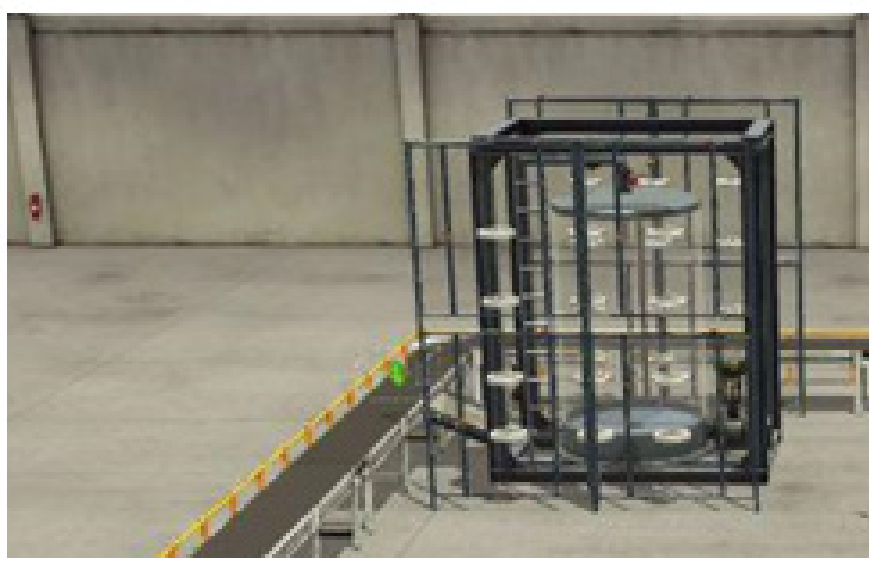

Figure 4: Front view of Knitting 4.0.

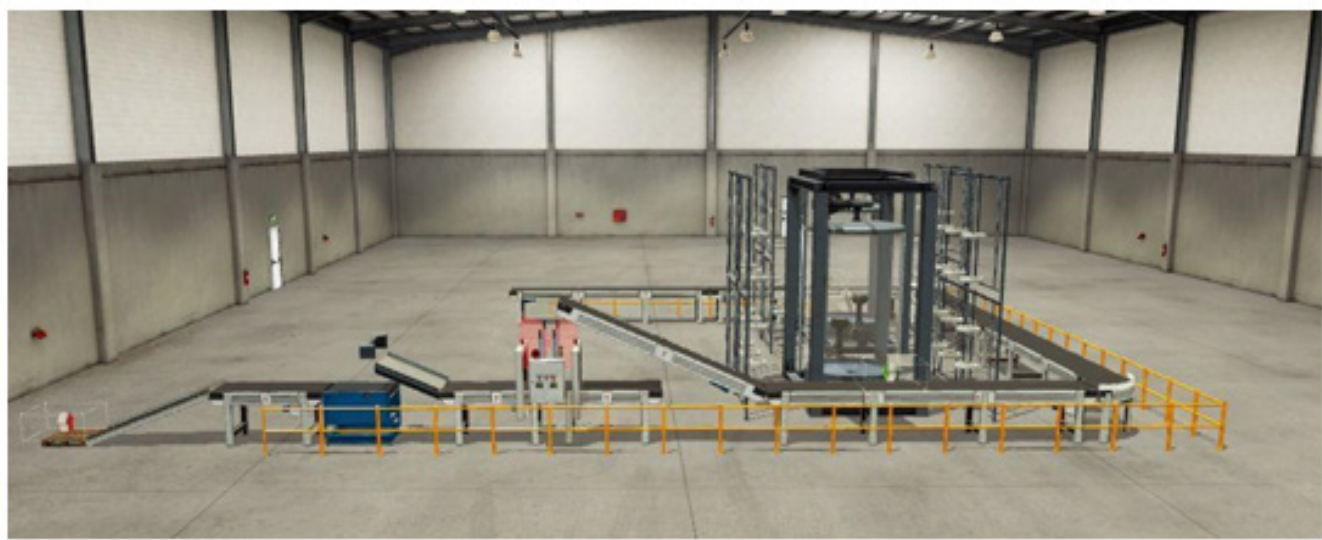

Figure 5: Lateral view of Knitting 4.0.

Figure 6: Illustration of the knitted fabric defect detection.
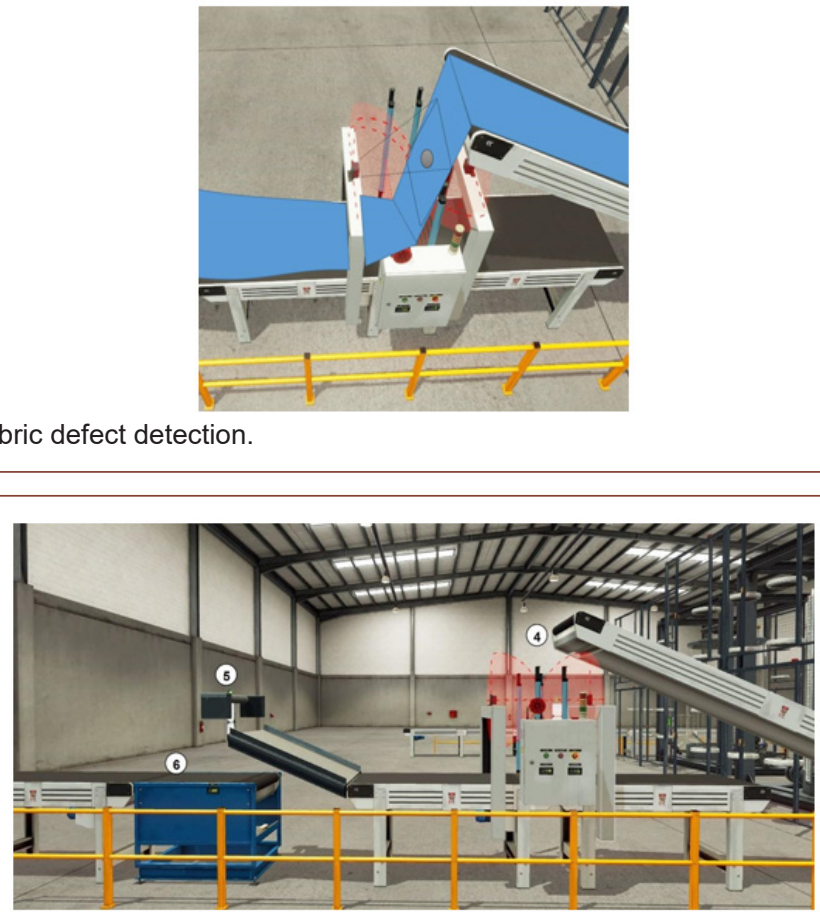

Figure 7: Finishing of the process: sensors, camera, winding and automatic balance. 
As seen in Figure 3, the Knitting 4.0 process works through an autonomous production line, not requiring the presence of the operator to carry out the process, which is aided by an automatic belt, represented by the number 1 , linked to the process from the beginning to the end. In this plan, after the production of the knitted fabric, the circular knitting machine, represented by the number 2 , automatically cuts the newly formed tubular knitted fabric. Number 3 consists of adding the QR CODE to the knitted fabric with relevant product information (pattern, yarn used, machine specification, customer, quantity). Then, with the help of a mechanical arm, the knitted fabric is guided to the automatic conveyor, which may be supported or already on the roll, depending on the type of knit fabric to be produced.

It should be noted that the circular knitting machine illustrated in Figure 3 must have the ability to automatically adjust cams and needles according to the pattern to be produced. This type of configuration is found in circular Jacquard knitting machines, which allow the formation of the most varied designs and patterns, as they adjust the positions of the needles via a computerized needle selecting system. This type of characteristic allows eliminating step 1 presented in Table 4.

Analyzing Figure 3, it can be seen that the loop failure control is performed (number 4), where the knitted fabric passes through sensors that detect non-conformities; a camera captures the failure identified by the sensor, recording it in the database from the company. Subsequently, the knitted fabric is carried by the belt in the direction of a second elevation, where the roll is formed, if it is in folded form. Finally, at number 5, a balance attached to the conveyor weighs the knitted fabric and displays the value, which is stored in the company's database, per batch produced.

The industrial plan of the proposed knitting, in front and lateral views, developed using the aforementioned software, from the concepts related to industry 4.0, can be seen in Figures 4 and 5, respectively.

Figure 5 presents the Knitting 4.0 plan in its lateral view, showing the part where the belt has elevations, precisely so that the knitted fabric passes through the sensors to detect failures and then be rolled up.

As previously mentioned, the knitted fabric defect detection system in conventional knitting process is carried out manually. In this proposal, the defect detection such as holes, thick and thin yarn,

barré, broken needle, among others, occurs through sensors, which detect irregularities. After detection, the sensor sends a signal to the camera positioned in front of the knitted fabric, registering the defect, along with its approximate size and location in the knitted fabric. This process is illustrated in Figure 6.

Figure 6 shows the gray circle, which illustrates a nonconformity found in the knitted fabric. The dotted square area refers to the comprehensive space of the camera, which captures the image, immediately after receiving a signal, through sensors, that the knitted fabric has a defect. In this configuration, the system needs to present a database of non-conformities, that is, of the defects that may occur in the knitted fabric production, so that it is possible to identify and classify the defect found and assist in decision making regarding the process, which can be sent to an online platform for real-time monitoring.

Summarizing the process, after the knitted fabric passes the elevation illustrated by number 4 (Figure 7 ), it is rolled up in position number 5 , weighed on the balance (number 6 ), and then taken to be automatically packed and placed on pallets, being available for shipment to the next manufacturing step. A logistical challenge would be to automate the process of removing the cones from the boxes and making them placed in the feeders. For this purpose, it is also foreseen the insertion of robots that aim to facilitate the activities, mainly with regard to the preparation of the circular knitted machine to start the production of the fabric. These robots, parallel or delta, contain 3 to 4 arms to perform activities 2 and 3 in Table 4, due to their characteristics (speed, precision of movements, axes of rotation and flexibility), which fit the needs of the tasks [28]. Thus, with an automated system, steps 2 and 3 are eliminated.

Therefore, analyzing Table 4 with the activities developed from Knitting 4.0, Table 6 is presented, with estimates of production times, based on the steps that were modified and eliminated with automation process.

It is worth mentioning that for production of the fabric in steps 5 and 10 (Table 6), an efficiency of $100 \%$ is estimated.

Thus, according to the batch formation restrictions for the subsequent processes, previously mentioned, Table 7 is presented with the times for manufacturing batches of 7 or 20 rolls, for the scenario of Knitting 4.0 compared to conventional models.

Table 6: Duration of production steps from Knitting 4.0.

\begin{tabular}{|c|c|c|c|}
\hline Step & Description & Time [min] & Comments \\
\hline 1 & $\begin{array}{l}\text { Positioning of cams according to the knitted fabric pattern that } \\
\text { will be produced }\end{array}$ & - & Automatically \\
\hline 2 & Placing yarn packages in the creel & - & Negligible \\
\hline 3 & Yarn passing through all knitting elements, (feeders and needles) & - & Negligible \\
\hline 4 & Initial tests and knitted fabric production & 2 & Checking for possible defects and adjustments \\
\hline 5 & Production of the first roll & 28 & $\begin{array}{l}\text { To produce } 16 \mathrm{~kg} \text { according to the technical data- } \\
\text { sheet (100\% efficiency) }\end{array}$ \\
\hline
\end{tabular}




\begin{tabular}{|c|c|c|c|}
\hline 6 & Cutting knitted fabric (after finished) & - & Not applicable \\
\hline 7 & Positioning of the newly produced knitted roll in the revisor & - & Only the first roll of each batch is reviewed \\
\hline 8 & Review and winding of the fabric & - & Not applicable \\
\hline 9 & Delivery of the finished knitted roll to the pallet & - & Not applicable \\
\hline 10 & Production of the subsequent knitted roll & 28 & $\begin{array}{c}\text { To produce } 16 \mathrm{~kg} \text { according to the technical data- } \\
\text { sheet (100\% efficiency) }\end{array}$ \\
\hline 11 & Cutting fabric (after finished) & - & Negligible \\
\hline 12 & Delivery of the finished knitted roll to the pallet & - & Negligible \\
\hline
\end{tabular}

Table 7: Production time by batch size and machine configuration.

\begin{tabular}{|c|c|c|c|c|}
\hline \multirow{3}{*}{ Knitting } & Setup & Batch size [rolls] & Total time[min] & Time/Roll [min] \\
\hline \multirow{3}{*}{ Conventional } & Complete & 7 & 484 & 69,1 \\
\cline { 2 - 5 } & \multirow{2}{*}{ Reduced } & 20 & 965 & 48,3 \\
\cline { 2 - 5 } & & 7 & 286 & 40,9 \\
\cline { 2 - 5 } & Automatic & 20 & 767 & 38,4 \\
\cline { 2 - 5 } & & 7 & 562 & 28,3 \\
\hline
\end{tabular}

It can be noted in Table 7, that the time per roll in Knitting 4.0 slight changes depending on the lot size. This is due to the fact that the setup is practically eliminated in the process, leaving only a small adjustment step at the beginning of production. In comparison with the shorter time per roll in the previously studied knitting industry, it is estimated a $27 \%$ reduction in automated one, which could speed up the payback of a possible investment in such a conventional knitting industry.

Therefore, among the benefits provided by this new knitting industrial plan, developed from concepts related to industry 4.0, the following stand out: speed in the transport of knitted fabric, due to the presence of automatic conveyors; the ergonomics factor is considered during the process, in order not to harm the worker's health; possibility of making real-time decisions directly from the factory floor, since the control of activities and the data provided allow the manager to monitor the data in real time, and thus, identify the defects as well as production bottlenecks; thorough control of non-conformities in each meter of the fabric produced due to the inspection of the knitted carried out automatically, with the aid of sensors, not harming human vision; storage of defects and process data; increased speed during setup due to the presence of robots; remote process monitoring.

Figure 8 illustrates schematically the connections among four main topics related to emerging technologies to obtain a sector driven by the concepts of the fourth industrial revolution: storage of data volume; connectivity and interoperability; robotics; and data analysis. The proposal of this Knitting 4.0 is innovative and following these global automation trends, offering a suggestion of inserting connected technologies to obtain superior gains in quality, productivity and social well-being.

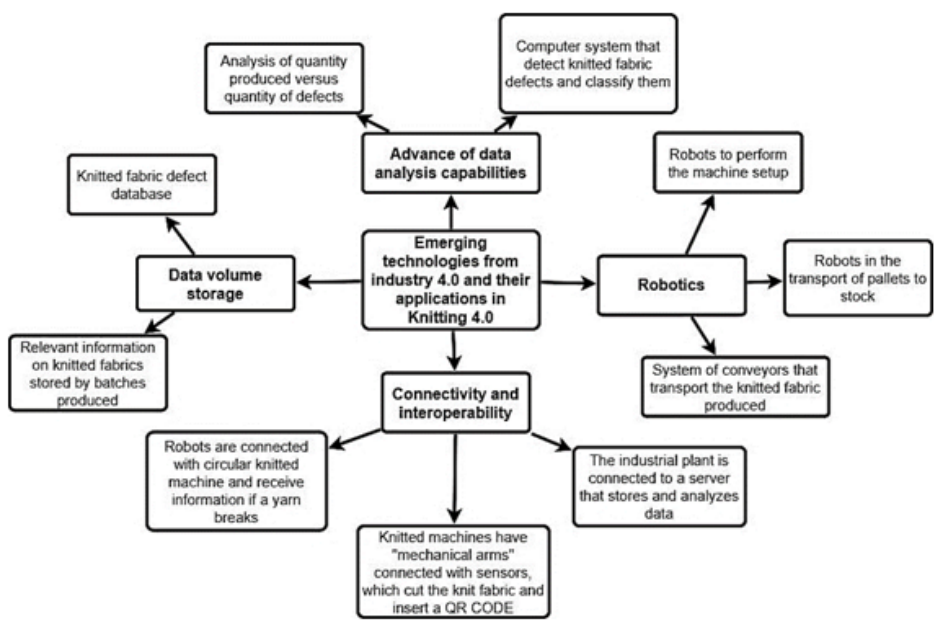

Figure 8: Connection among the emerging technologies applied in Knitting 4.0. 
It is important to observe reservations to make the concept of Knitting 4.0 a reality: the issue was reduced to just one type of knitted fabric, based on the practical reality of a specific company.

It was also considered that there is technological capacity available to automate some steps described in Table 6, as well as the possibility of reaching an optimal situation of $100 \%$ efficiency during knitting production. In conventional processes, there is great participation by the operator, since there is a need to exchange defective and worn needles, as well as replacement of broken yarns. It would be a great challenge to eliminate these losses and machine downtime, and achieve 100\% efficiency, through the synchronized operation of robots.

With regard to the yarns used in circular knitting, the company analyzed reports that some brands and types of yarns are processed more efficiently on certain models and brands of circular knitting machine. This means that even if the same knitted fabric pattern is performed on two knitted machines with identical specifications, but of different brands, there may be changes in production times. Likewise, producing a knitted fabric patterns on a specific machine, but with different brand yarns, can also result in divergent products. It would then be necessary to develop a study in conjunction with potential yarn manufacturers.

It is also reported by mechanics that the use of package with different yarn counts in a given knitted pattern can change the performance of the knitting machine, since they are a function of the gauge. Even the number of monofilaments can indicate different production times for the same pattern and composition. Thus, it is known that the complexity of yarn technology for knitting is an extremely relevant factor in the development and validation of a Knitting 4.0, which would require further study.

In addition, there are other steps that are unlikely to eliminate human interference, such as making the yarn package available on the knitting machine, as a result of all the raw material logistics designed for the operators.

Therefore, the potential for increased efficiency obtained with the implementation of a Knitting 4.0 is imminent. The possibility of eliminating specific steps in the production process can be decisive in the validation of automation technologies. On the other hand, one cannot ignore the diversity and complexity existing in the product development and, mainly, in the manufacture of a textile substrate using knitting technology.

\section{Conclusion}

This study conceptualized the complexity of the textile chain, its ramifications and opportunities and the importance of this sector for Brazil and the world.

Due to the scope of the knitting technology, it was tried to reduce the problem to a specific type of knitted pattern, as well as to obtain empirical production data from a knitting company, to provide parameters for comparison with improvements resulting from automated processes.

Using the Factory $I O \circledR$ software, a new configuration was developed for the knitting sector, called "Knitting 4.0", since it uses emerging technologies inserted in the industrial plan, in order to improve the process as a whole, from quality of the final product to the health and well-being of the operators in this sector. In addition, the paper follows the trends of the global industrial market, in which the automation of processes is increasingly visualized.

According to the suggestions mentioned, there was an industrial gain in time of approximately $27 \%$ compared to the current scenario - which can be further optimized. In addition, it is estimated that the employee who previously performed manual tasks, can now act in the analysis of the database, observing new ways to avoid defects in the fabrics, development of new knitted patterns, in addition to preventing the emergence of problems related to labor ergonomics.

However, challenges and limitations were raised that reinforce the idea that some steps of production will be performed essentially by human labor. In addition, the complexity of manufacturing a circular knitting product does not cease to exist in a Knitting 4.0, as there are extremely relevant parameters in the raw material and knitted pattern.

\section{Acknowledgement}

The authors kindly thank CAPES Foundation, Ministry of Education.

\section{Conflicts of Interest}

The authors declare no conflicts of interest.

\section{References}

1. Ganzer PP, Chais C, Olea PM (2017) Product, process, marketing and organizational innovation in industries of the flat knitting sector. RAI Revista de Administração e Inovação 14(4): 321-332.

2. Zhao H, Lin B (2019) Resources allocation and more efficient use of energy in China's textile industry. Energy 185: 111-120.

3. Majumdar A, Sinha SK (2019) Analyzing the barriers of green textile supply chain management in Southeast Asia using interpretive structural modeling. Sustainable Prod Consumption 17: 176-187.

4. Lin B, Chen Y, Zhang G (2018) Impact of technological progress on China's textile industry and future energy saving potential forecast. Energy 161: 859-869.

5. Kao HL, Chaung CH, Chang LC, Cho CL, Chiu HC (2019) Inkjet-printed silver films on textiles for wearable electronics applications. Surf Coat Technol 362: 328-332.

6. Küsters D, Prass N, Gloy YS (2017) Textile Learning Factory 4.0 Preparing Germany's Textile Industry for the Digital Future. Procedia Manuf 9: 214-221.

7. Ali A, Haseeb M (2019) Radio frequency identification (RFID) technology as a strategic tool towards higher performance of supply chain operations in textile and apparel industry of Malaysia. Uncertain Supply Chain Management 7: 215-226.

8. (2020) ABIT (Brazilian Textile and Apparel Industry Association). Perfil do Setor. 
9. Lucato WC, Costa EM, Neto GCO (2017) The environmental performance of SMEs in the Brazilian textile industry and the relationship with their financial performance. J Environ Manage 203(Part 1): 550-556.

10. Xie Y, Guan Y, Kim S, King MW (2016) The mechanical performance of weft-knitted/electrospun bilayer small diameter vascular prostheses. J Mech Behav Biomed Mater 61: 410-418.

11. Tiwari SK, Fei PTC, McLaren JD (2013) A pilot study: Evaluating the influence of knitting patterns and densities on fabric properties for sports applications. Procedia Eng 60: 373-377.

12. Nayak R, Kanesalingam S, Vijayan A, Wang L, Padhye R, et al. (2017) Design of 3D knitted structures for impact absorption in sportswear DesTech Conference Proceedings 2: 127.

13. Sahkti P, Sangeetha K, Bhuvaneshwari M (2016) Development of Double Layer Knitted Fabric for Sportswear Using Tencel/Polypropilenefibres. International Journal of Current Pharmaceutical Review and Research. 8: $30-34$.

14. Steffens F, Oliveira FR, Mota C, Fangueiro R (2017) High-performance composite with negative Poisson's ratio. J Mater Res 32: 3477-3484.

15. Asimakopoulos S, Asimakopoulos G, Spillers F (2017) Motivation and User Engagement in Fitness Tracking: Heuristics for Mobile Healthcare Wearables. Informatics 4: 5.

16. Xie J, Long H (2014) Equivalent resistance calculation of knitting sensor under strip biaxial elongation. Sensors and Actuators A: Physical 220 118-125.

17. Yetisen AK, Martinez-Hurtado JL, Ünal B, Khademhosseini A, Butt $H$ (2018) Wearables in Medicine. Adv Mater 30(33): 1-26.

18. Filho WL, Ellams D, Han S, Tyler D, Boiten VJ, et al. (2019) A review of the socio-economic advantages of textile recycling. J Cleaner Prod 218 10-20.

19. Öztürk N, Esin MN (2011) Investigation of musculoskeletal symptoms and ergonomic risk factors among female sewing machine operators in Turkey. Int J Ind Ergon 41(6): 585-591.

20. Melzer ACS (2008) Physical and organisational risk factors associated to work-related musculoskeletal disorders in textile industry. Fisioterapia e Pesquisa 15: 19-25.
21. Maciel ACC, Fernandes MB, Medeiros LS (2006) Prevalence and factors associated with pain symptoms in professionals of the textile industry. Rev Bras Epidemiol 9: 94-102.

22. Meena ML, Dangaych GS (2015) An Ergonomic Approach to Design Hand Block Tool for Textile Printing Handicraft Industry. Int J Rec adv Mech Eng 4: 19-30.

23. Soytas U (2006) Physical and ergonomic hazards in the textile, chemical, food, metal products, and woodworking industries in Turkey. Int J Occup Environ.Health 12(1): 35-41.

24. Kabir SMM, Zakaria M (2012) Effect of Machine Parameters on Knit Fabric Specifications. DUET Journal 1: 12-16.

25. Vargas S, Stivanello EM, Masson JE (2014) Development of an automatic mesh fabric inspection system. Conference on Graphics Patterns and Images 1: 1-4.

26. Nardo MD, Forino D, Murino T (2020) The Evolution of man-machine interaction: the role of human in Industry 4.0 paradigm. Prod Manuf Res 8(1): $20-34$

27. Kamble SS, Gunasekaran A, Sharma R (2018) Analysis of the driving and dependence power of barriers to adopt industry 4.0 in Indian manufacturing industry. Comput Ind 101: 107-119.

28. Michalos G, Kousi N, Karagiannis P, Gkournelos C, Dimoulas K, et al. (2018) Seamless human robot collaborative assembly - An automotive case study, Mechatronics 55: 194-211.

29. Moktadir MA, Ali SM, Kusi-Sarpong S, Shaikh MAA (2018) Assessing challenges for implementing Industry 4.0: Implications for process safety and environmental protection. Process Saf Environ 117: 730-741.

30. Vaidya S, Ambad P, Bhosle S (2018) Industry 4.0 - A Glimpse. Procedia Manuf 20: 233-238.

31. Rauch E, Linder C, Dallasega P (2020) Anthropocentric perspective of production before and within Industry 4.0. Comput Ind Eng 139: 1-15.

32. (2020) ABIT (Brazilian Textile and Apparel Industry Association). 